\title{
MANAGEMENT ISSUES
}

\section{Purchasing new equipment}

The wide range of equipment required in a modern $A \& E$ department reflects both the diversity and rapidly expanding nature of our specialty. I feel I ought to come clean from the outset and declare my interest in gadgets and admit that I am fair game for the representative with the latest gizmo. However, a practical and common sense approach to ordering and reordering equipment is required.

The first step is to know what works and what is unreliable or no longer fulfils requirements. A useful approach is a regular, preferably annual, review of all existing equipment and maintenance contracts, comparing service record and cost of maintenance verses frequency of use and effectiveness. Old and inefficient equipment with high maintenance costs and dubious reliability can then be decommissioned. Equipment that is worn out can be replaced.

The annual stock taking should take into account the views of colleagues from other specialties who most frequently use the equipment. These views will produce some surprises and prevent expensive mistakes. A phased replacement of some equipment may be needed to ensure that multiple units do not wear out at the same time.

As far as possible one should plan for future need and bear in mind that the least glamorous piece of equipment may be the most essential. Nevertheless, charitable donations, particularly from grateful relatives, will usually have to be spent on more conspicuously "life saving" equipment. In my experience, Mrs Smith takes some persuading that a new inspection lamp is your most essential requirement when she wishes to purchase a defibrillator like the one used during valiant attempts to (unsuccessfully) cardiovert her husband.

A review of equipment should not seek to retire reliable "old friends," as old equipment, if well maintained, will often perform as well as its latest and brightly painted offspring. The serviceability of old equipment should be considered in the light of the latest health and safety regulations and guidelines of the Committee on Substances Hazardous to Health (COSHH) should also be heeded. Be honest with yourself and separate the Needs from the Wants and draw up a short "wish" list. Now consider funding.

We all work within cost constrained environments, although in every trust there is an annual allocation for new and replacement equipment, and just like the National Lottery - it could be you!

Every institution differs, although there are some general principles. Equipment costing less than $£ 300$, for example, can be purchased from the A\&E budget direct. Equipment costing less than $£ 5000$ should be purchased from revenue, which in theory comes from profits made from contracts with the purchaser. Equipment of more than $£ 5000$ has to be bid for through the business plan and is thus a capital development. It is worth remembering that the details of this equipment are kept in a general register and are liable for capital charges at $6 \%$ of the written down value over a 10 year period. These capital charges are pay- able to NHS central funds and are held over for funding replacement equipment in the future.

A properly argued case, suitably supported by other specialties, will always triumph over a hastily written proposal without any clear recommendation or true understanding of all the costs involved. It is worth remembering that even the most expensive piece of equipment for an A\&E department pales into insignificance when compared with some of the requests from other departments.

From the short list of needs will emerge some front runners, arrived at through consultations that may severely test your negotiating skills. The golden rule is that the views of the main users of the equipment shall be paramount. A selection of manufacturers should then be invited to demonstrate their goods. Any company who is not prepared to allow a trial of use should be politely shown the door. At this point inquire whether any "nearly new" or "last year's model" equipment is available. These purchases can represent extremely good value and, if well looked after, can be indistinguishable from new. If I may borrow a slogan, "forget when it was built, consider who built it."

Find out from the salesperson if other trusted colleagues are using this model and make inquiries at that department. Assessment should be for a reasonable period and include every clinical setting in which it will be used. Compare equipment from different manufacturers. Seek opinions from everyone, including the night staff and occasional users from other departments. The nursing staff are likely to be the greatest users of any equipment and hence should have the largest say.

During this time the true cost should emerge, including that of essential peripherals and reusables. The "best buy" may have a high cost in reusables with a resultant large recurring dent in your budget. Revenue costs frequently outweigh initial capital expenditure. Going out to tender through the supplies department can bring some surprise cost reductions or turn up other models that escaped your consideration.

Your preference for a small lightweight and portable monitor may be rejected in favour of something larger, although ultimately more utilitarian. Your final choice should reflect all opinions or you will end up with a technological marvel which, while appealing to you personally, may be deemed unusable and user unfriendly. It will gather dust on the shelf. A flexible approach is required.

After the final selection, a statement of need is required. This should be short and descriptive of how the selected item is essential for good clinical care and be endorsed by any evidence based medicine supporting the proposal. Before writing it, seek advice from the Chair of the medical equipment committee as to how the statement should be prepared. Anaesthetists have many similar equipment requirements and the opinion of an anaesthetic "heavyweight" will always be useful. Overall the more widely you consult with colleagues the more likely your project will succeed. The emphasis should always be upon the essential nature of the equipment and how it will benefit your patients. 
If relevant, the opinion of the medical physics department should be sought, as their experience of the cost of reusables and service contracts is invaluable. Maintenance contracts can be punitive.

If no alternative finance is available, the statement has to take its chance with other bids. Sometimes it is preferable to ask the senior nursing staff to complete the process, as a well argued case by the "end user" will have great influence.

It is possible to persuade patients' relatives or charities to let you hold funds over, while saving for the remainder. A word with your finance director should ensure charitable status and avoidance of VAT. Remember that "one off" donations, no matter how generous, will not cover recurring revenue costs. The cost of equipment we use most frequently in $A \& E$ is usually within the grasp of a medium sized charitable event and as a result A\&E has become a popular recipient of such benefactors. Across the board, about $30 \%$ of the costs of new equipment comes from charity monies.

The high profile that our specialty now enjoys makes the task of influencing outside charities and agencies more fruitful. An invitation to speak at a round table dinner or Rotary Club lunch may well bear fruit at a later date.
The trust will have a list of local charities which contribute towards equipment. The League of Friends and WRVS are usually very generous and should be approached. The equipment committee is usually well disposed to an offer of partial funding.

Patients like to support their local hospital, and sponsored events often bring forth sizeable funds. The local press is usually friendly and may help in advertising a fund raising exercise. This makes good copy and an approach to the editor is worthwhile.

If equipment is purchased through these routes, ensure that a small plaque is attached and the equipment is handed over at a suitably high profile ceremony. Invite the media and be prepared to speak.

Nurturing a charitable trust in this way may bring forth other gifts at a later date.

Return to the salesperson once the money is secured and negotiate hard. A sharp intake of breath and a sigh at the first price will usually bring about a reduction but don't forget about the extras. Remember caveat emptor and a consensus decision based upon hands on use. Good luck!

C D H OAKLAND Bristol

\section{Disciplinary procedures}

It is a sad but inevitable fact of professional life that disciplinary procedures are necessary.

The medical profession works within clear margins of what is and is not acceptable, derived from a combination of professional standards and the General Medical Council (GMC). It has always had wide tolerance levels of behaviour, but public demands and expectations, as well as an increasingly litigious climate, mean that these levels are narrowing. Disciplinary procedures should serve as a warning, set out a system by which problems can be dealt with, and help to protect individuals by laying down specific regulations and guidelines.

\section{General principles}

It is important to distinguish between personal and professional misconduct. All of us who work in medicine are governed by the same moral and ethical principles as those affecting all citizens and we have no right to be treated differently. NHS trusts have a set of disciplinary procedures for all employees who behave badly or inappropriately. The medical profession is bound by such procedures.

Such procedures for personal misconduct range from a minor reprimand to immediate dismissal. For example, a doctor may steal or commit violence. The fact that such a misdemeanour occurred in a hospital is of no relevance. However, to prescribe illegally for example, necessitates the possession of a medical degree. If the difference between personal and professional misconduct is not straightforward, the question to ask is "does the possession of a medical degree make any difference to this misbehaviour?"

\section{Professional misconduct}

The formation of Trusts means that all nationally and previously agreed procedures are rewritten locally. Such rewriting follows discussions between the profession and local management (usually represented by the personnel depart- ment). To enable this process, local negotiating committees have been formed, elected by and representing all doctors.

For a single or repeated minor offence, for example constant late attendance or rudeness, it may be necessary to issue a written warning. This procedure is delegated to the medical director, or deputy, by the chief executive. The warning should indicate its duration and is included in the personal file of the doctor-rather like points on a driving licence. These remain confidential within the Trust. Oral warnings can be issued but they are kept off the personal record.

The medical director will be at the hub of any investigations concerning more serious allegations of professional misconduct or incompetence. Such allegations can come from any source and should be passed directly to the medical director.

Procedures will vary, but generally the medical director will consult the personnel director and the chairman of the hospital medical staff committee (CHMSC) who will investigate the allegations. Subsequent actions will depend on their findings.

(1) Nothing proven. No further action taken.

(2) Resolution of the problem on an informal basis. This often requires a meeting between the various parties with a check on the situation after three to six months.

(3) Personal misconduct or failure to complete job plans requires further action (that is, a written warning to change behaviour and further monitoring).

(4) If the allegation warrants further disciplinary action, an investigative hearing should be held between the medical director and personnel director with the doctor, who has the right to be represented by a friend, professional colleague, or representative. The next stage requires that the practitioner is notified of all charges and a disciplinary hearing is convened. Witnesses are called and the hearing is conducted along the lines of the Trust's policies. The practitioner 